\title{
The Development of Science Process Skills and Academic Achievement in Chemistry of Matthayom Sueksa Five Students at Ramkhamhaeng University Demonstration School Using the Peer-Assisted Technique.
}

Maneerat Sa-ngiamjit,

\begin{abstract}
In this research investigation, the researcher compares (1) the academic achievement in organic chemistry of selected Matthayom Sueksa Five students instructed by means of the peer-assisted technique. The researcher also describes and analyzes (2) the fostering of science process skills of these students utilizing the peer-assisted technique.

Using the simple random sampling method, the researcher selected a sample population constituting a single Matthayom Sueksa Five (Science-Math) classroom at the Ramkhamhaeng University Demonstration School (DSRU) of such students enrolled in the second semester of the academic year 2015. The research instruments consisted of an academic achievement test on organic chemistry couched at the validity level of 0.82 and a test used for measuring science process skills couched at the validity level of 0.75 .

Using techniques of descriptive statistics, the researcher analyzed the data collected in terms of mean and standard deviation. A t-test technique was also employed by the researcher.

Findings are as follows:

(1) The students taught using the peer-assisted technique exhibited a higher level of academic achievement in organic chemistry after the study was completed than prior to the commencement of the study at the statistically significant level of .05.

(2) After the completion of the study, these students showed improvement in science process skills at the statistically significant level of .05 .
\end{abstract}

Keywords: Science Process Skills, students, peer-assisted technique, academic achievement

\section{Introduction}

Science have an important role in the world today and the future. The science involves everyone both the daily and professional services as well as technology and various productivity tools many people used to facilitate life and work. These are the result of scientific knowledge combined with creative and other disciplines. The purpose of science have made students to learned science on the links with the knowledge and process involved in the learning process. It made with real action to suit a variety of levels. [1]

The development of teaching so that students acquire knowledge the skills and scientific 
attitude have higher achievement can arrange for students to participate in most activities and take action on their own. Teachers are those who have a critical role in promoting learning and development activities for the students to learn science process skills and have fun in learning science to achieve the goals set course. [2]

Science process skills is a key factor in the study of scientific knowledge because scientific knowledge gained from the study at different times, it is reliable or not. Apart from the study will be used, how reliable it. Researcher will have to learn the skills or the ability to perform the study at that time a smooth transition. The information in each step is reliable and because we think human beings have different aptitudes and abilities innate inborn but that does not mean that the difference will not be updated or developed. The current study found that the ability or skills can practice and develop to achieve it. Therefore, the development of science process skills to learners achieve proficiency. Optional skills to properly solve each side, it can be done as well. It is evident that developing science process skills to the learners. Teachers will find a way to develop students' skills in the various fields. The students learning by choosing the right way and can solve problems that occur. [3]

Organic chemistry is the study many properties of substance has a carbon atom is the main component. Organic refers to the body or the life of the organic matter is a story that involves the creature. The study of these substances are essential to the development of industry and technology. In addition, studies to understand the properties should be understood that the bonding between atoms of the molecule's shape. To understand the properties of organic matter deeply. In the process of teaching the course in organic chemistry, it is important to make the students' attention. And learning increase the knowledge can be adapted to everyday life can be. [4]

Peer-Assisted Technique, This is a way of learning to help each other to process of working together allow students to share their learning in the interdependent. Thus, researcher use it to provide students with the knowledge and understanding of the content can apply their knowledge to help explain and exchange with weak academic performance to achievement of better. [5]

Previously, the researchers conducted a study on the teaching of Inquiry. The Inquiry is a process or technique of teaching the students to focus on one form of self-knowledge using the scientific process as a means to acquire new knowledge. After teaching teacher evaluation by commissioning the exercises and tests showed that some students can not do the exercises and exams have not passed a certain threshold. This problem is due to some students who learn slowly. And the ability to learn as well so I had to find a way to motivate students to be interested and encourage students to be more active. PeerAssisted Technique is a way to help support such an approach is the one, the friend has a key role in learning. Friends and influential in creating interest, motivation and recognition of friends together. Peer-Assisted Technique is the group activities, learning in small groups or studying together a handy way to identify good academic help friends to make a weak academic performance improves. By requiring students have good academic as leaders to help guide explains various topics to the friends group does not understand, stay tuned to help them understand the intimacy and closeness of the group who have a sense of self and acceptance would result in the development of better achievement. 
The researchers have used Peer-Assisted Technique in teaching organic chemistry for students get the knowledge of organic chemistry possible. Through education and intellectual development of Cognitive Domain was devoiced 6 stage by Benjamin S. Bloom, which including knowledge comprehension application analysis synthesis and evaluation to help in the design achievement tests in the course thereof and knowledge can be utilized to carry out their own lives. Also, the learning and teaching chemistry have fun, not stressful, even more enthusiastic and ready to apply the knowledge that their research be explained to members and friends in the audience. To enhance their knowledge in the course of organic chemistry increased is the activities in small groups. The students participate in activities to help each other rotation in go of teachers and learners in group to gain a better understanding of the organic chemistry. The teacher's role is to provide advice and learning activities to suit learners. The researchers have achievement test to students also found that a lack of knowledge in addition to teachers and teaching and the lack of ideas and approaches to problem solving. In addition, the researchers observed a learned behavior of students throughout the class found that most students have negative attitudes towards learning organic chemistry and lack of skills to learn many things. The researchers found that the skills that are easy to add good attitude towards learning organic chemistry. The observation skills and classifications skill are basic skills. In addition, interpretation and conclusions skills is the integration skills. This skill is a skill to add comments to the data obtained from the observations rationally on previous experience or knowledge to help in the analysis. Summary relationships data, summary of data from trials or studies is evident that developing science process skills to students that teachers must find ways to develop students' skills in the various fields. The students learning by choosing the right way and can solve problems and develop skills to increase the scientific process.

\section{Research Objectives}

In this research investigation, the researcher compares (1) the academic achievement in organic chemistry of selected Matthayom Sueksa Five students instructed by means of the peer-assisted technique. The researcher also describes and analyzes (2) the fostering of science process skills of these students utilizing the peer-assisted technique.

\section{Population and sample size Population}

The population in this research is 87 person, three Matthayom Sueksa Five (science - Math) at Ramkhamhaeng University Demonstration school in the second semester of the academic year 2015.

\section{Sample Size}

The sample used in this research is a student at Ramkhamhaeng University Demonstration school in the second semester of the academic year. One of three rooms by means of simple random sampling. 


\section{Focused Variables}

Variables focused in the study is how to learn together in a peer learning activities.

The dependent variable was the learning behavior of the students. The details are as follows:

1. Achievement of Organic Chemistry.

2. Science Process Skills

\section{Outputs and Benefit}

According to the study, overall achievement of students who have been taught using Peer-Assisted Technique before - after learning basic organic chemistry Taught by a peer learning activities.r

1. Students are developing their own learning is better. Can think critically and solve problems from the study of organic chemistry.

2. Good achievement students can chance to expand their knowledge to their friends and help a friend who has mild learning. Students have benefited from the weak and the opportunity to gain experience in solving the problem in several ways.

3. Students can work well with others, adapt to society show the opinion and comments with classmates.

4. Students understand the culture of others even have good relationship Entente. Despite fundamental differences to solve problems, which helps them develop important life skills.

5. The atmosphere in the classroom is to have fun.

\section{Research Tools}

The tools used in this research is divided into two categories consist the tools used in the trial and the tools used to collect data. The details are as follows:

1. The instruments used in the trial, including lesson plans. The scientific activities of Matthayom Sueksa Five (science - Math) is "Organic Chemistry" each lesson plans are divided into five basic activities include the training the match learners the practice dating the team won and advanced testing, which has led Peer-Assisted Technique for developed science process skills which according the content.

2. The instrument used to collect the data were collected.

2.1. Achievement Test on organic chemistry 4 choices 40 items.

2.2. Test the science process skills.

\section{Research Methodology}

Created tools and methods to ensure the quality of the tools.

1 Plan, which has led the Peer-Assisted Technique for developed science process skills in teaching developing science process skills.

1.1 Educational textbooks and research papers related to the creation of lesson plans using Peer-Assisted Technique. 
1.2 Education core curriculum for basic education in 2008 group learning science. University School curriculum documents, books and research-related activities, Peer-Assisted Technique. To guide in defining the concept of essence, purpose, content and learning activities.

1.3 The structure and content to be created lesson plans using a Peer-Assisted Technique. The key elements of the learning plan.

- Main idea

- Purpose of leaning

- Learning

- Integrated approach

- Learning process

- Media / Learning Resources

- Methods of Measurement and Evaluation

- Observation form working group

- Teaching record

hour.

1.4 Create lesson plans using a Peer-Assisted Technique include 8 plans total 18

1.5 Bring lesson plans using a Peer-Assisted Technique offered to three professionals to check for accuracy. Content validity consistency between activities, learning objectives and learning by coming to the IOC (Index of Item Objective Congruence) the purpose and content of the learning activity.

1.6 Improvement Plan course about organic chemistry under the guidance of experts.

1.7 Plan to bring about organic chemistry course, updated as research tools.

2. Achievement Test

The researcher test the learning sciences. There are procedures to follow.

2.1 Documentation and research on vertical measurement and evaluation achievement of Learning Sciences Institute of Science and Technology.

2.2 Analysis of the content and purpose of learning activities to create a test achievement chemistry, organic chemistry, knowledge types to choose four options divided by the desired behavior is measured in six areas: knowledge, comprehension, application analysis and evaluation.

2.3 Construction of test achievement Chemistry of Organic Chemistry choose four options on the table analysis test of 40 questions.

2.4 Take the quiz achievement chemistry, organic chemistry, created to provide expert scientific learning of three professionals check the empirical validity. The results of the audit to improve the tests. Then came the consistency index (Index of Item Objective Congruence: IOC) has the consistency index $\geq 0.5$ are considered to have consistency in the acceptance criteria.

2.5 Achievement Test to be amended, to students at six schools University. This is not the sampling. And learn about organic chemistry already. And determine the scoring. Scoring of answer sheets by being 1 score for right answer to a wrong answer or not answer more than one question to 0 score.

2.5.1 Determine the level of difficulty of the achievement test have difficulty item $(\mathrm{P})$ ranged from 0.20 to 0.80 . 
2.5.2 Check for discrimination by ensuring that student achievement tests to identify talented students and how well the technique of using the discrimination of 0.20 or more, which is a good test can be used. To determine the discriminative power ( $\mathrm{r}$ ) of the tests used in this discrimination from 0.20 and up.

2.5.3 Check out the reliability is checked to measure the confidence that regular and constant using Cronbach's Alpha Coefficient using SPSS statistical software, which the reliability was 0.95 .

2.6 Techniques taught by Peer-Assisted Technique and quizzes before - after study. The process of teaching and learning in Matthayom Sueksa Five (Science-Math) classroom at the Ramkhamhaeng University Demonstration School (DSRU)

3. Test the science process skills to create a scientific process skills test multiple choice answers are the steps to create a tool used in the study.

3.1 determine the aim of creating a scientific process skills test multiple choice.

3.2 theoretical studies and research papers related to science process skills test multiple choice and content of science subjects at Matthayom Sueksa Five (ScienceMath) classroom to guide the creation of the test.

3.3 Writing definition of the science process skills test multiple choice.

3.4 Construction of the science process skills test in accordance with definitions, terminology and content of science.

3.5 Lead science process skills test scientific process created to provide expert scientific learning of three professionals check the empirical validity. The results of the audit to improve the tests. Then came the consistency index (Index of Item Objective Congruence: IOC) has the consistency index $\geq 0.5$ are considered acceptable in accordance with the IOC ranged from 0.66 to 1.00 .

3.6 Leading test capabilities and improve the science process skills to students at Matthayom Sueksa Five (Science-Math) classroom. This is not the sampling and determine the scoring. Scoring of answer sheets being 1 score for right answer to a wrong answer or not answer more than one question to 0 score.

3.6.1 Check out the reliability is checked to measure the confidence that regular and constant using Cronbach's Alpha Coefficient using SPSS statistical software, which the conviction was 0.95 .

3.7 Leading science process skills test. The amendment was put to the test sample.

\section{Data Collection}

This research study focused on the development and achievement of science process skills. Of students at five schools University. It operates as follows.

1. Education and behavior of student to lead research

2. Student test achievement test measurement and science process skills in science teaching.

3. Course conducted by the plan using Peer-Assisted Technique. While teachers observe and record the behavior of the students.

4 When all lesson plans and teaching. Student test achievement. Measurement and process skills in science classes. Using test the same as the previous test. 
5. Teachers keep score of the test before and after learning. The average was taken for comparison.

\section{Data Analysis}

Trial schemes applied by conventional research Randomized Control Group Pretest-Posttest Design.

Comparative analysis of the science process skills of students before and after teaching of average user standard deviation and t test.

Data analysis comparing the achievement of Chemistry. Matthayom Sueksa five student at pretest and posttest using average user standard deviation and t test.

\section{Results}

Table 1 compares the achievement of Organic Chemistry. Students of five years with a Peer-Assisted Technique before and after learning

\begin{tabular}{lccll}
\hline \hline Test & $\mathrm{N}$ & $\overline{\mathrm{X}}$ & S.D. & $\mathrm{t}$ \\
\hline Previous & 40 & 25.75 & 6.87 & $9.803^{*}$ \\
After studying & 40 & 53.81 & 16.70 & \\
\hline \hline
\end{tabular}

* There is a statistically significant level. 05.

Table 2 compares the science process skills of high school students five years with a Peer-Assisted Technique before and after learning

\begin{tabular}{|c|c|c|c|c|c|}
\hline \multirow[t]{2}{*}{ Skills } & \multicolumn{2}{|c|}{ pretest } & \multicolumn{2}{|c|}{ posttest } & \multirow[t]{2}{*}{$\mathrm{t}$} \\
\hline & $\overline{\mathrm{X}}$ & S.D. & $\overline{\mathrm{X}}$ & S.D. & \\
\hline observation & 7.56 & 3.56 & 15.81 & 3.89 & $9.93^{*}$ \\
\hline classification. & 3.62 & 2.11 & 14.44 & 2.74 & $22.67 *$ \\
\hline Interpretation and conclusion & 3.31 & 2.15 & 9.25 & 3.21 & $10.27 *$ \\
\hline Total basic skills & 14.56 & 4.07 & 39.38 & 9.69 & $16.05^{*}$ \\
\hline
\end{tabular}

* There is a statistically significant level. 05.

\section{Conclusions and Discussion}

Students have been learning activities using Peer-Assisted Technique. Achievement of learning about organic chemistry after higher than the previous level of statistical significance. 05 .

Achievement before class had an average of 25.75, standard deviation of 6.87 for achievement after classes had an average score of 51.44 and a standard 
deviation of 15.05 showed a standard deviation after class higher than the previous classes show that Peer-Assisted Technique with student high academic can develop themselves better than students with low academic performance. The distribution is clearly different to make the standard deviation is higher than it was prior to the achievement of the experimental group had higher scores than the previous statistically significant at the .05 level. Peer-Assisted Technique make students help together between good academic students with weak academic students to help children be obedient. Describe the contents in homework to some person do not understand each other. As a result, the learning outcomes of children obedient better than before using Peer-Assisted Technique. Beginning Knowledge or what we knew before when the team arrived to help bring awareness to it or knowledge of the other assembly knowledge we have. It will have some knowledge of our knowledge and the knowledge of others is the same knowledge. When you know each other, it will cause. "New knowledge" is another chunk of knowledge that can contribute to the performance eventually. The group process to help students with the knowledge, understanding can vary. Exchanged views and support among colleagues. The researchers divided the group easily. The number of members in groups of 3-4 people, group members will help weak academic students. Helping each other to resolve the problem by doing the exercises lesson to take the test when you finish the lesson better than the usual classroom lecture. This is consistent with research of Chiwan Boonton [6] using of Peer-Assisted Technique to increase reading comprehension in English and a self-esteem. The sample of students at grade 4 of graduate student are learning English, reading and writing (Eng 025) Sanpatong School. San Pa Tong district Chiang Mai, totaling 18 people, the researchers found that students learn strategies to help a friend an understanding of English reading and looking self-esteem was higher than before the experiment.

2. Students have been learning activities using a Peer-Assisted Technique science process skills after high school before studying at a statistically significant level. 05 .

Science process skills of students after learning activities with learning, peer learning higher level of statistical significance. 05 The results of the analysis before and after the study. The average overall science process skills and science process skills by earning higher learning. The science process skills pretest averaged 14.56 points, standard deviation, 4.07 points for the science process skills classes with an average of 39.38 points and a standard deviation of 9.69, it is the science process skills of Matthayom Sueksa Five after learning activities with University of graduate student higher learning. There are three skills: 1) observation skills with the previous have an average of 7.56 points, standard deviation was 3.56 points and after classes have an average of 15.81 points and the standard deviation was 3.89 points ahead to notice that most students will respond using only the senses, but when using a Peer-Assisted Technique. Students will have the information from observations more because, the answer response from the students to share their learning with each other. Students use multiple senses the resulting observation skills of students in Matthayom Sueksa Five classes higher than the previous 2) classifications skill have average pretest was 3.62 points, standard deviation 2.11 points and posttest have an average score of 14.44 points and 2.74 of standard deviations. Observed before learning found that students have the ability to break down the of classification skills criteria that teachers only. But when using a Peer-Assisted 
Technique students have the ability to break down the skills of classification criteria that determine a teacher and the students have a good criteria because students have to know each other through the exchange of skills in a group of friends. The classification skill of Matthayom Sueksa Five classes higher than the previous 3) interpretation and conclusions skills with the previous 3.31 points, standard deviation 2.15 points, and after learning valuable. average 9.25 points and the standard deviation 3.21 points previous observation that students have the ability to interpret and the conclusions skills tend to put personal opinions into it, but when using Peer-Assisted Technique students have academic increased because there is an exchange student experience and to gather ideas from the group. Teachers must not only focus on the students to feel or see it. As a result, the skills of interpretation and concluded with the students. As a result, the classification skills of Matthayom Sueksa Five students after high school before classes. This is because Developing science process skills by learning a Peer-Assisted Technique better every skill. Corresponding with Chanikran Thaworrayutikran consistent with research amulet satyr found that science process skills of students in the two classes after using a series of activities to develop the scientific process higher than before. The level of statistical significance results of 05 [7] and Arunya Phasanklong found that the average academic achievement, skills, process integration, and the creativity scientific activities of the science process skills integration of students grade 1 at one school after high school before a statistically significant level of 01 [8]

\section{Recommendations}

1. Suggestions for further usage of the research results

1. Teachers should help students and consultant on the issue.

2. In the event may have to be modified to suit the abilities and interests of students.

3. Teachers should prepare the equipment and chemicals used in the trial and should be treated first in order to be aware of the problems and solutions.

4. Teachers should be evaluated for each group to improve and develop yourself to the point where they are disadvantaged.

5. Teachers should have a role in facilitating student learning should be encouraging students to express their opinions and group process to train students to leave a comment.

\section{Suggestions for further research.}

1. There should be a study to investigate the use of other activities. In order to improve achievement and science process skills and updated to suit the students.

2. To study the relationship between theory and practical skills.

\section{References}

[1] The Ministry of Education. (2008). The Basic Education Core Curriculum 2008. Thailand, 106.

[2] Department of Education. (2002). A Guide to Learning. Group learning science. Bangkok; Thailand. 
[3] T. Pongkun. (2015). Best practice. Thailand Abstract.

[4] Mahidol Wittayanusorn School. Organic Chemistry. Department of chemistry, Thailand. (2011) 1.

[5] W. Soranaruk. (2011). The Development of Learning Achievement on Microeconomics I by Using Peer Assisted Learning (PAL) for Accounting Students. Suan Dusit University, Thailand.

[6] C. Boonton. (2003).Using peer learning strategies to increase reading comprehension in English and a self-esteem. Thailand.

[7] C. Thaworrayutikran. (2005). Results of activity Science Process Skills Integrated Science Process Skills to integrate and creativity of the students at first. Sukhothai Thammathirat Open University. Thailand.

[8] A. Phasanklong. (2005). The teaching lab analysis framework for the science process skills and capabilities in analytical thinking that segment of the student's grade 5. Ban Nong Hoi Chaiyapbum. Sukhothai Thammathirat Open University, Thailand. 